\title{
Effect of Enzymatically Hydrolyzed Lignin on the Curing Characteristics of Epoxy Resin/Polyamine Blends
}

\author{
Sen Wang, ${ }^{\text {a }}$ Yayun Lai, ${ }^{a}$ Yalan Yu, ${ }^{\text {a }}$ Mingwei Di, ${ }^{\text {a,* }}$ and Junyou Shi ${ }^{\text {b,* }}$ \\ Corn stalk enzymatically hydrolyzed lignin (EHL) was used to modify \\ bisphenol A-type epoxy resin. The curing reaction processes of the epoxy \\ resin/polyamine blends and the lignin/epoxy resin/polyamine blends were \\ studied via isothermal differential scanning calorimetry (DSC), and the \\ effect of enzymatically hydrolyzed lignin on the curing reaction of epoxy \\ resin was also analyzed. The results showed that the curing kinetics for \\ two blends were not in full compliance with the autocatalytic curing kinetic \\ model, especially the lignin/epoxy resin/polyamine blends. The apparent \\ activation energy of the epoxy resin/polyamine blends increased with the \\ increased presence of the lignin. The presence of enzymatically \\ hydrolyzed lignin was beneficial to the curing process of epoxy \\ resin/polyamine blends at high temperatures. The addition of the lignin \\ increased the final curing reaction conversion rate, improved the glass \\ transition temperature $\left(T_{\mathrm{g}}\right)$ and increased the bending strength for the \\ epoxy resin/polyamine blends. However, the impact strength decreased in \\ this process.
}

Keywords: Lignin; Blends; Differential scanning calorimetry (DSC); Curing kinetics; Epoxy resins

Contact information: a: Key Laboratory of Bio-based Material Science \& Technology (Ministry of Education), Northeast Forestry University, Harbin, China; b: Jilin Provincial Key Laboratory of Wooden Materials Science and Engineering, Beihua University, Jilin, China;

*Corresponding authors: dimingwei@126.com; jlshijunyou@yahoo.com.cn

\section{INTRODUCTION}

Lignin is the only non-petroleum biomass resource that can provide renewable aromatic compounds. Thus, lignin is regarded as one of the most promising future organic resources (Laurichesse and Avérous 2014). Generally, lignin is produced largely as a byproduct of plant hydrolysis in the paper and bioethanol industries. The most important chemical functional groups in the lignin molecule's structure include the aromatic group, hydroxyl, methoxyl, carbonyl, and carboxyl groups (Saito et al. 2013; Ghaffar and Fan 2014). Thus, lignin can be used as an organic raw biomass material for the modification of polymers. Currently, the development and application of lignin has been of great interest to researchers due to its multitudinous advantages, such as abundancy, low cost, biodegradability, and renewability (Gosselink et al. 2004; Cavdar et al. 2008; Ibrahim et al. 2013; Zhang et al. 2015).

In several common industrial lignins, enzymatically hydrolyzed lignin (EHL) has recently received considerable attention, due to its high purity and high reactivity with respect to the curing of resins (Mansouri and Salvadó 2007). As a by-product of the biomass conversion industry, EHL possesses greater chemical activity and applicability than lignosulfonate or kraft lignin (Hatakeyama et al. 2004; Mansouri and Salvadó 2007). The reason is that the enzymatic hydrolysis process of biomass was carried out under relatively mild conditions, and many functional groups, such as phenolic hydroxyl and alcoholic 
hydroxyl, were well preserved. Therefore, EHL could be used as active fillers or modifiers to improve the properties of polymer materials by directly blending with polymers.

Epoxy resin is a type of cross-linked polymer that possesses excellent chemical resistance, good electrical insulating properties, and good adhesion to glass, metals, and so on. These properties help epoxy resin to meet the performance requirements of some demanding applications. These include areas as diverse as construction, electronics, adhesives, and coatings (Musto et al. 2007; Zheng et al. 2009; Saad et al. 2011). In epoxy resin cross-linked polymers, the additive agents, such as the curing agent and the filler, play a decisive role for the resin properties. Using lignin as a filler or modifier agent through blending with epoxy resin, with the reactive groups of lignin and its phenolic ether structure, the mechanical and thermal properties of epoxy resin can theoretically be improved. The above judgment was also confirmed by previous studies (Malutan et al. 2008; Stewart 2008; Mansouri et al. 2011; Khalil et al. 2011; Wood et al. 2011). As a polyphenolic compound with many active functional groups, lignin would certainly influence the curing reaction between epoxy resin and the curing agent, and the performance of the cured product would be influenced accordingly. However, most of the relevant research relates to the macroscopic mechanical performances and thermal characterizations for epoxy resin blending with lignin, and the relevant research about the effect of lignin on the curing reaction of epoxy resin is limited (Feldman and Banu 1988; Feldman et al. 1991).

The authors' previous studies indicated that EHL can cure epoxy resin, but the result for curing is not satisfactory. For example, a high curing temperature and a long curing time were required for curing, and the cured product was brittle (Yin et al. 2012). The experiments showed that the addition of EHL influenced the curing reaction between epoxy resin and the polyamine curing agent. Therefore, this research will be focused on the curing process of the EHL/epoxy resin/polyamine blends, using the isothermal DSC method to study the curing reaction characteristics of epoxy resin/polyamine blends with the presence of highly purified EHL, which could be beneficial to the practical application of epoxy resin-polyamine blends.

\section{EXPERIMENTAL}

\section{Materials}

Highly purified corn stalk enzymatically hydrolyzed lignin was provided by Laihe Chemicals Co., Ltd. (Songyuan, China). It was dried at $50{ }^{\circ} \mathrm{C}$ for $24 \mathrm{~h}$ in a vacuum oven before blending. General bisphenol A-type epoxy resin (E-51) with an epoxy value of 0.51, was provided from Xingchen Synthetic Material Co., Ltd. (Nantong, China). The curing agent polyamine was purchased from YanHai Chemical Co., Ltd. (Tianjin, China). The curing agent polyamine is a polycondensate of dimer linoleic acid and triethylene tetramine. Some characteristics of the polyamine, epoxy resin and lignin are listed in Table 1. The viscosity was determined by a NDJ-5S model rotational viscometer (Shanghai Pingxuan Scientific Instrument Co. Ltd., Shanghai, China) according to ASTM D1084-16 (2016). The detail structure information of the polyamine is shown in Fig. 1. A Netzsch D204 model differential scanning calorimeter (DSC) system provided by Netzsch Scientific Instruments Co., Ltd. (Selb, Germany) was used to analyze the curing reaction of epoxy resin. 
Table 1. Characteristics of the Polyamine and the Epoxy Resin

\begin{tabular}{|c|c|c|c|c|c|}
\hline \multicolumn{2}{|c|}{ Polyamine (TY-200) } & \multicolumn{2}{c|}{ Epoxy Resin (E-51) } & \multicolumn{2}{c|}{ EHL } \\
\hline $\begin{array}{c}\text { Amine value } \\
(\mathrm{mg} \mathrm{KOH} / \mathrm{g})\end{array}$ & $\begin{array}{c}200 \text { to } \\
230\end{array}$ & $\begin{array}{c}\text { Epoxy value } \\
(\mathrm{Eq} / 100 \mathrm{~g})\end{array}$ & $\begin{array}{c}0.52 \text { to } \\
0.54\end{array}$ & $\begin{array}{c}\text { Acid value } \\
(\mathrm{mg} \mathrm{KOH} / \mathrm{g})\end{array}$ & 95.8 \\
\hline $\begin{array}{c}\text { Viscosity } \\
\left(\mathrm{mPa} \cdot \mathrm{s} / 25^{\circ} \mathrm{C}\right)\end{array}$ & $\begin{array}{c}10000 \text { to } \\
80000\end{array}$ & $\begin{array}{c}\text { Viscosity } \\
\left(\mathrm{mPa} \cdot \mathrm{s} / 25^{\circ} \mathrm{C}\right)\end{array}$ & $\begin{array}{c}12500 \text { to } \\
13700\end{array}$ & $\begin{array}{c}\text { Hydroxyl value } \\
(\mathrm{mg} \mathrm{KOH} / \mathrm{g})\end{array}$ & 44.6 \\
\hline Molecular weight & $\begin{array}{c}1000 \text { to } \\
1500\end{array}$ & Molecular weight & $\begin{array}{c}350 \text { to } \\
400\end{array}$ & Molecular weight & $\begin{array}{c}100 \text { to } \\
8000\end{array}$ \\
\hline
\end{tabular}

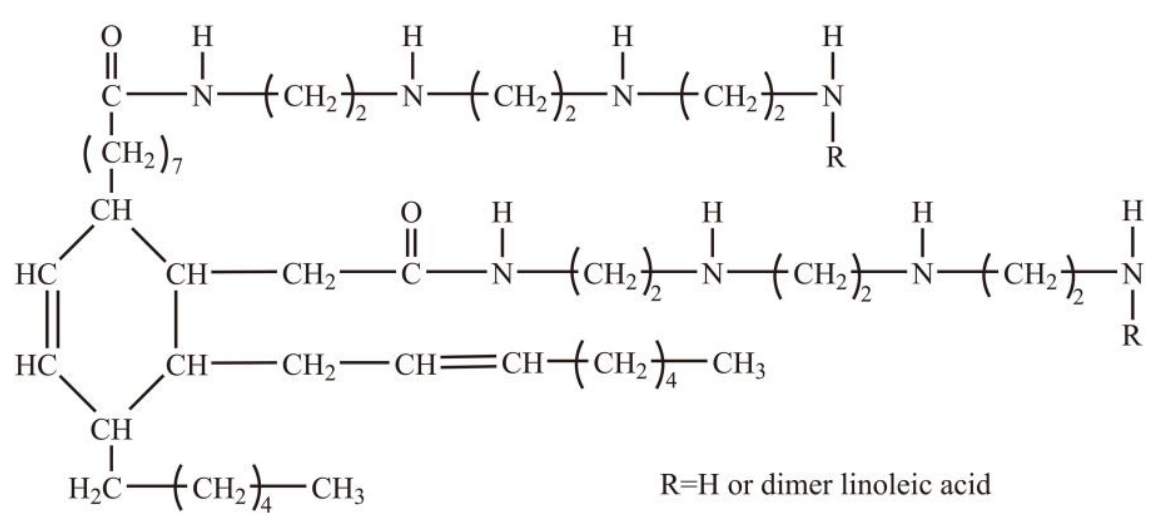

Fig. 1. Chemical structure of the polyamine

\section{Preparation of the blends}

The amount of polyamine used was based on Eq. 1 (Wang 2001),

Amount of Polyamine $(\mathrm{phr})=\left(56100 \cdot\right.$ “epoxy value") / ("amine value"' $\left.f_{\mathrm{n}}\right)$ (1)

where 56100 is the equivalent weight $(\mathrm{mg})$ of $\mathrm{KOH} ; f_{\mathrm{n}}$ equals $(n+2) /(n+1),(n$ represents the number of $-\mathrm{CH}_{2}-\mathrm{CH}_{2}-$ minus 1 ), $n$ is 2 for triethylene-tetramine, and then $f_{\mathrm{n}}$ equals to 1.33 .

The weight ratio of the polyamine and epoxy resin of 1:1 was employed, while the theoretical amount of the polyamine is $94.65 \%$ to $113.04 \%$ to epoxy resin (E-51) by weight. The viscosity of the blends will increase observably due to the addition of lignin powder into the epoxy resin. A weight ratio of 1:9.5:9.5 for EHL:epoxy resin:polyamine was chosen. The epoxy resin and polyamine were mixed at a weight ratio of 1:1, then mixed uniformly at room temperature, air bubbles were removed via a vacuum, and the mixture was labelled as EP. The blend of EHL, epoxy resin, and polyamine was mixed at a weight ratio of 1:9.5:9.5 according to the same procedure as the EP did, which was labelled as L/EP.

\section{Methods}

DCS analysis

Firstly, EP and L/EP were scanned by a non-isothermal method at the heating rate of $5 \mathrm{~K} / \mathrm{min}$ in an air atmosphere, and the quality of the sample was chosen as $5 \mathrm{mg}$ to 10 $\mathrm{mg}$. Secondly, for isothermal experiments, the scanning temperatures of $105{ }^{\circ} \mathrm{C}, 115^{\circ} \mathrm{C}$, and $125^{\circ} \mathrm{C}$ were chosen for EP and L/EP, respectively (Vyazovkin et al. 2011), and the 
time chosen for the constant temperature stage was $6 \mathrm{~h}$. The samples were scanned at the rate of $30 \mathrm{~K} / \mathrm{min}$ before reaching the isothermal cure temperature. The $T \mathrm{~g}$ were measured in a second heating from $25{ }^{\circ} \mathrm{C}$ to $250{ }^{\circ} \mathrm{C}$ at the rate of $20 \mathrm{~K} / \mathrm{min}$.

Using DSC analysis to study the curing kinetics and determine the kinetic parameters of the curing reaction process is a common method (Karkanas and Partridge 2000; Ghaffari et al. 2012). In the DSC test of the curing for epoxy resin, the reaction heat is proportional to the amount of reactive epoxy groups, i.e. the reaction heat $\Delta H$ is proportional to the extent of conversion $\alpha$, and the extent of conversion $\alpha$ can be expressed as the Eq. 2,

$$
\alpha=\frac{\Delta H_{t}}{\Delta H_{o}}
$$

where $a$ is the extent of conversion, $\Delta H_{t}$ is the enthalpy of reaction at time $t$, and $\Delta H_{0}$ is the total enthalpy of reaction.

During isothermal curing reaction, the reaction rate and the DSC heat flow $d H / d t$ can be expressed by Eq. 3 .

$$
\frac{\mathrm{d} \alpha}{\mathrm{d} t}=\frac{\mathrm{d} H}{\mathrm{~d} t} \frac{1}{\Delta H_{O}}
$$

After measuring the total enthalpy of reaction $\Delta H_{0}$, according to the results of isothermal DSC, the correlativity between not only the rate $d \alpha / d t$ and the time $t$, but also the extent of conversion $\alpha$ and the time $t$ could be obtained. The correlativity between $d \alpha / d t$ and $\alpha$ could also be obtained (Vyazovkin and Sbirrazzuoli 2006). In general, the effect of the conversion rate and temperature on the curing reaction rate can be expressed by Eq. 4 (Vyazovkin et al. 2011),

$$
d \alpha / d t=k(T) f(\alpha)
$$

where $k(T)$ expresses the reaction rate constant in connection with the temperature and is generally written as an Arrhenius relation,

$$
k(T)=A \exp \left(\frac{-E a}{R T}\right)
$$

The parameter $f(\alpha)$ describes the conversion dependence and is related to the reaction mechanism, $\alpha$ is the extent of conversion, $A$ is the pre-exponential factor, $E_{a}$ is the apparent activation energy, and $R$ is the universal gas constant.

There has been a lot of research conducted about the curing kinetics of epoxy resin/amine blends. From previous studies, there are two common curing kinetic models according to the difference of the curing reaction process: $n$-order reaction model and autocatalytic reaction model (Du et al. 2004; Xu et al. 2004; Harsch et al. 2007; Vyazovkin et al. 2011; Vafayan et al. 2013; Zvetkov and Calado 2013). The kinetic equation of the $n$ order reaction model can be expressed as Eq. 6,

$$
\frac{d \alpha}{d t}=k(1-\alpha)^{n}
$$

where $k$ is the reaction rate constant and is generally written as an Arrhenius relation, $\alpha$ is the extent of conversion, and $n$ is the reaction order. The characteristic of the $n$-order reaction model is that the initial reaction rate is the fastest, and the reaction rate decreases with increasing reaction time. 
Most epoxy resin curing reactions conform to the autocatalytic reaction model. The change with respect to time can be described as in Eq. 7,

$$
\frac{d \alpha}{d t}=k \alpha^{m}(1-\alpha)^{n}
$$

where $k$ is the reaction rate constant, $\alpha$ is the extent of conversion, and $m$ and $n$ are the reaction orders. An autocatalytic reaction has a reaction induction period, where the curing reaction rate reaches a maximum when the reaction continues for a period of time, and the isothermal DSC curve has a peak, and the $\alpha-t$ curve has a typical sigmoid shape (Vyazovkin et al. 2011).

\section{Mechanical properties}

The bending strength of the samples was tested according to ASTM D790-10 (2010) by using a CMT-6104 electronic universal testing machine (Shenzhen Reger Instrument Co. Ltd., China). And the non-notched Izod impact strength of the samples was tested according to ASTM D256-10 (2010) by using a XJC-25Z pendulum impact testing machine (Chengde Experiment Machine Co. Ltd., China). All measurements were tested under ambient conditions with a relative humidity of approximately 50\%. At least five samples were tested for each formulation.

\section{RESULTS AND DISCUSSION}

\section{Determination of the Total Heat of Reaction}

The total enthalpy of EP and L/EP were measured by a non-isothermal DSC method. The result is shown in Fig. 2. The enthalpy of the reaction could be worked out directly in the Netzsch D204 model DSC system. The curing reaction enthalpy of EP was $\Delta H_{\mathrm{EP}}=288 \mathrm{~J} / \mathrm{g}$ and the curing reaction enthalpy of L/EP was $\Delta H_{\mathrm{L}-\mathrm{EP}}=282 \mathrm{~J} / \mathrm{g}$, which agrees with the typical value $(250 \mathrm{~J} / \mathrm{g}$ to $311 \mathrm{~J} / \mathrm{g}$ ) for conventional epoxy-polyamine polymerizations (Sun and Zhang 2009). The initial reaction temperature $T_{\mathrm{i}}$, peak temperature $T_{\mathrm{p}}$, end temperature $T_{\text {end }}$, and the reaction enthalpy are listed in Table 2.

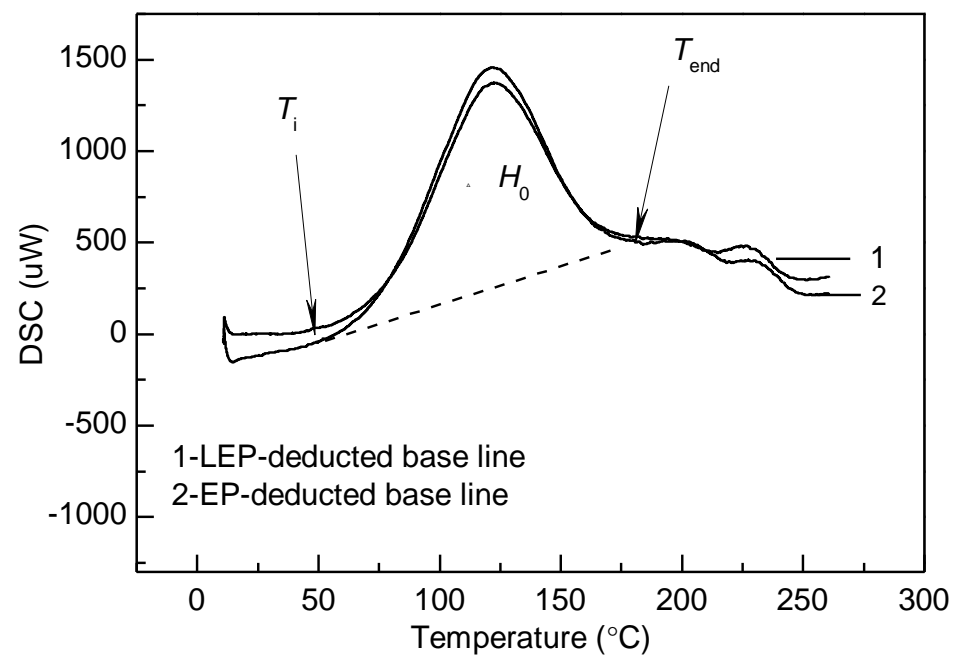

Fig. 2. Non-isothermal DSC curves of EP and L/EP at the rate of $5 \mathrm{~K} / \mathrm{min}$ 
Table 2. Non-isothermal Curing Characteristics of EP and L-EP at $5 \mathrm{~K} / \mathrm{min}$

\begin{tabular}{|c|c|c|c|c|}
\hline \multirow{2}{*}{ Sample } & \multicolumn{4}{|c|}{ Curing Peak Characteristics } \\
\cline { 2 - 5 } & $T_{\mathrm{i}}\left({ }^{\circ} \mathrm{C}\right)$ & $T_{\mathrm{p}}\left({ }^{\circ} \mathrm{C}\right)$ & $T_{\text {end }}\left({ }^{\circ} \mathrm{C}\right)$ & $\Delta H_{0}(\mathrm{~J} / \mathrm{g})$ \\
\hline EP & 61 & 121 & 166 & 288 \\
\hline L/EP & 58 & 122 & 172 & 282 \\
\hline
\end{tabular}

\section{Isothermal DSC Tests}

To ensure the complete reaction of epoxy resin within the experimental time, a higher reaction temperature should be chosen because of the low reactivity of epoxy resin/polyamine blends. According to Fig. 2 and the results in Table 2, the temperatures $105{ }^{\circ} \mathrm{C}, 115^{\circ} \mathrm{C}$, and $125{ }^{\circ} \mathrm{C}$ were selected as the isothermal DSC temperatures. A secondary non-isothermal DSC test was conducted on the test samples again after the isothermal DSC test to identify if there was residual reaction enthalpy. Due to the high reaction temperature and long reaction time selected in this study, no residual enthalpy was detected at the second scan, which suggested that the polyblends reached a considerable degree of crosslinking during the isothermal tests.

The isothermal DSC test results of EP and L/EP are shown in Fig. 3. In the DSC curves, the DSC heat flow $\mathrm{dH} / \mathrm{dt}$ indicated the reaction rate; the flattening of the curve indicated that the curing reaction tended to be over. As shown from the curve, with the increase of reaction temperature, the DSC heat flow $\mathrm{dH} / \mathrm{dt}$ increased, which showed that the reaction rate increased after raising the curing temperature. The curves flattened quickly at a higher temperature, which showed that the reaction tended to end quickly.
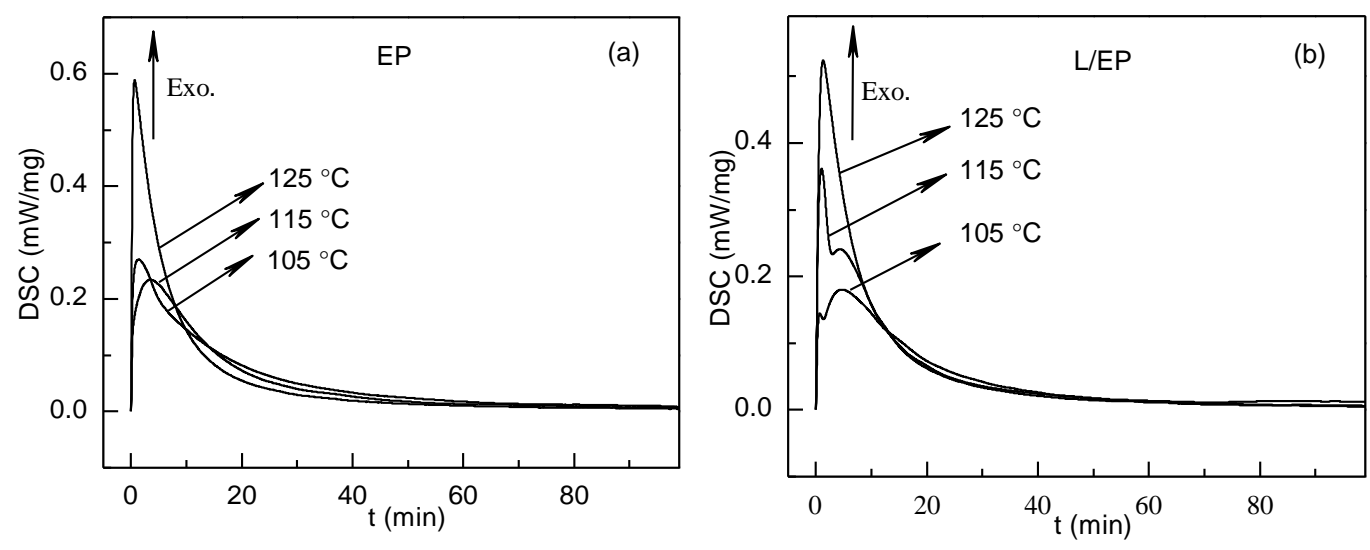

Fig. 3. Isothermal DSC curves of EP (a) and L/EP (b) blends

\section{Influence of Temperature on the Extent of Conversion $\alpha$}

As is known, the extent of conversion $\alpha$ is proportional to reaction enthalpy. Thus, the relationship of $\alpha$ and $t$ can be obtained according to the isothermal DSC curves. The results are shown in Fig. 4 and Table 3.

Table 3. Final Reaction Extent of Conversion for EP and L/EP Blends

\begin{tabular}{|c|c|c|}
\hline \multirow{2}{*}{ Temp. $\left({ }^{\circ} \mathrm{C}\right)$} & \multicolumn{2}{|c|}{ Extent of Conversion } \\
\cline { 2 - 3 } & EP & L/EP \\
\hline 105 & 0.78 & 0.67 \\
\hline 115 & 0.79 & 0.75 \\
\hline 125 & 0.82 & 0.88 \\
\hline
\end{tabular}


Figure 4 indicates that the reaction tended to be faster and more sufficient at a higher temperature.
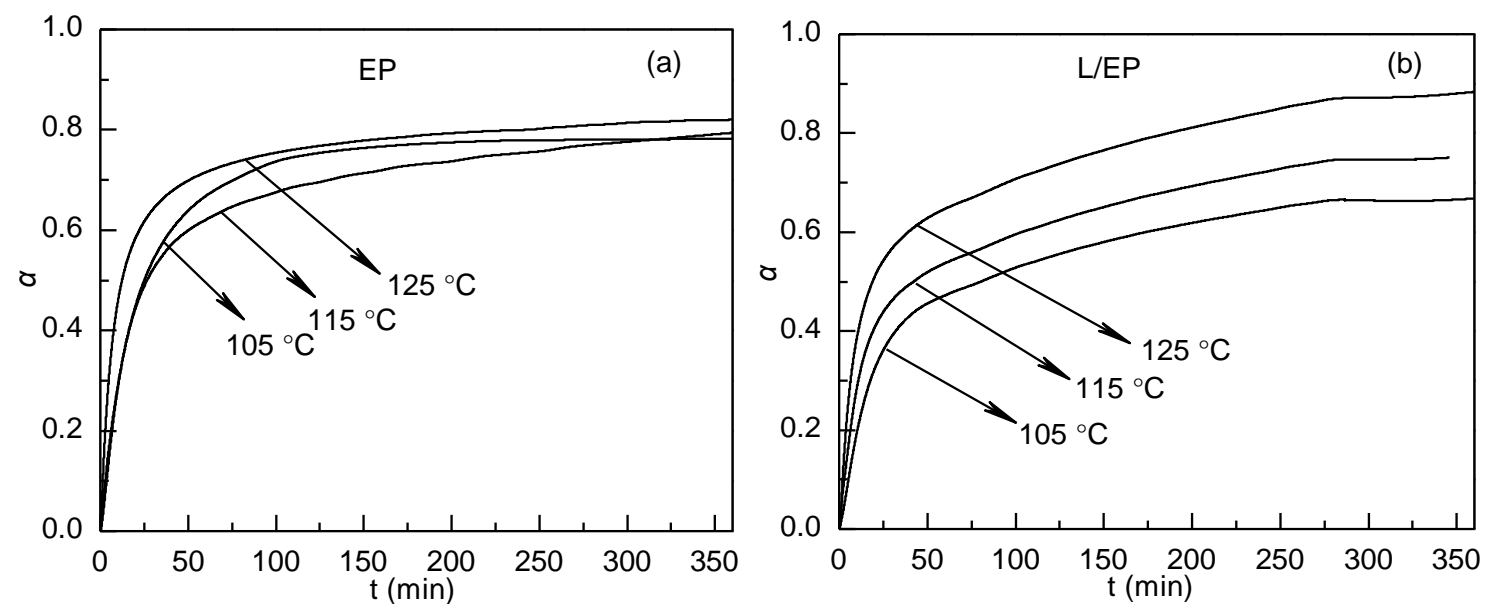

Fig. 4. $\alpha$ - $t$ curves of EP (a) and L/EP (b) blends

Table 3 also shows that the extent of conversion $\alpha$ of the EP blends increased with increased reaction temperature, but the increase was not large and the extent of conversion $\alpha$ of the EP blends did not exceed 0.9 under the selected experimental conditions. However, the final extent of conversion for the blends changed after the addition of lignin. When the reaction temperature was $105^{\circ} \mathrm{C}$ and $115^{\circ} \mathrm{C}$, the extent of conversion of the L/EP was lower than EP blends, respectively; but when the reaction temperature reached $125^{\circ} \mathrm{C}$, the extent of conversion of the L/EP blends was higher than that for the EP blends. The above results showed that the lignin was conducive to improve the curing reaction degree of epoxy resin/polyamine blends at high temperatures. The reason for this result may be that the involved lignin acts as an epoxy resin curing catalyst or as a structural part of the epoxy resin curing product to participate in the curing reaction (Yin et al. 2012).

\section{Glass Transition Temperature}

The test results of the glass transition temperature $\left(T_{\mathrm{g}}\right)$ for EP blends and L/EP blends are shown in Table 4. The results showed that the presence of the lignin in epoxy resin enhanced the $T_{\mathrm{g}}$ of the epoxy resin curing product. The above-mentioned results also verified the addition of the lignin had an influence on the curing reaction between the epoxy resin and polyamine curing agent.

Table 4. Glass Transition Temperatures for EP Blends and L/EP Blends

\begin{tabular}{|c|c|c|}
\hline Curing Temp. $\left({ }^{\circ} \mathrm{C}\right)$ & $\mathrm{EP}\left({ }^{\circ} \mathrm{C}\right)$ & $\mathrm{L} / \mathrm{EP}\left({ }^{\circ} \mathrm{C}\right)$ \\
\hline 105 & 51 & 52 \\
\hline 115 & 57 & 58 \\
\hline 125 & 58 & 62 \\
\hline
\end{tabular}

\section{Curing Reaction Kinetics}

Figure 5 shows the experimental and fitting curves of the reaction rate, $\mathrm{d} \alpha / \mathrm{d} t$, versus the extent of conversion, $\alpha$, for the epoxy/polyamine blends with and without the lignin at the isothermal DSC scan temperature of $125^{\circ} \mathrm{C}$. 

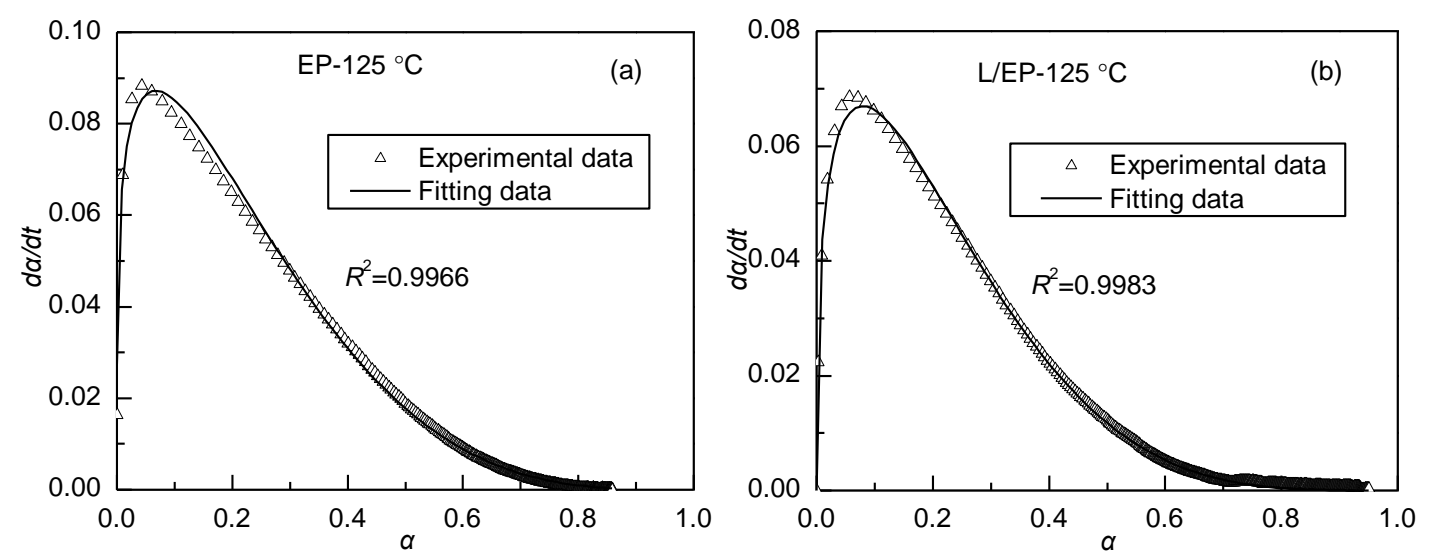

Fig. 5. Experimental data and fitting curve of reaction rate and conversion rate of EP (a) and L/EP (b) at $125^{\circ} \mathrm{C}$

As noted earlier, the n-order reaction model is characterized by a maximum reaction rate at the initiation period of reaction (Abenojar et al. 2014). The largest reaction rate $\mathrm{d} H / \mathrm{d} t$ occurred at $t=0$ on the isothermal DSC curves. The autocatalytic curing reaction is typically used for curing reactions that are characterized by a maximum reaction rate at approximately $30 \%$ to $40 \%$ progress (Abenojar et al. 2014). The isothermal DSC curve has a peak and the $\alpha$-t curve has a typical sigmoid shape. As shown in Fig. 5, the reaction had the characteristics of an autocatalytic reaction except for the presence of an induction period. This was because the presence of a short rise in temperature during the isothermal DSC test. In this study, the temperature-rise time for the isothermal DSC test was about $2.5 \mathrm{~min}$ to $3 \mathrm{~min}$, and the induction reaction for curing took place during the temperaturerise period of the isothermal DSC test. Thus, no induction period was reflected in Figs. 4 and 5.

Table 5. Isothermal Curing Kinetic Parameters of EP and L/EP at Different Temperatures

\begin{tabular}{|c|c|c|c|c|}
\hline \multirow{2}{*}{$\begin{array}{c}\text { Temp. } \\
\left({ }^{\circ} \mathrm{C}\right)\end{array}$} & \multicolumn{4}{|c|}{ Isothermal Curing Kinetic Parameters } \\
\cline { 2 - 5 } & ${\mathrm{k} / \mathrm{s}^{-1}}^{5}$ & $m$ & $n$ & $\mathrm{~m}+n$ \\
\hline \multicolumn{5}{|c|}{ EP Blends } \\
\hline 105 & 0.0742 & 0.1784 & 2.837 & 3.015 \\
\hline 115 & 0.1387 & 0.4115 & 3.646 & 4.058 \\
\hline 125 & 0.2075 & 0.2422 & 3.341 & 3.583 \\
\hline \multicolumn{5}{|c|}{ L/EP Blends } \\
\hline 105 & 0.0718 & 0.3007 & 4.243 & 4.544 \\
\hline 115 & 0.1077 & 0.2511 & 4.247 & 4.498 \\
\hline 125 & 0.2134 & 0.3358 & 3.846 & 4.182 \\
\hline
\end{tabular}

The autocatalytic model (Eq. 6) was found to describe the data seemingly well. A nonlinear multiple regression method based on Origin 8.5 was used to compute the three parameters $k, m$, and $n$ from the experimental data. The results are shown in Table 5.

According to the Arrhenius equation,

$$
k=A \exp \left(\frac{-E_{\alpha}}{R T}\right)
$$


where $k$ is the reaction rate constant, $A$ is the pre-exponential factor, $E_{\mathrm{a}}$ is the apparent activation energy, and $R$ is the universal gas constant. To take its natural logarithm on both sides of Eq. 7, Eq. 8 is derived as shown below.

$$
\ln k=\ln A-\frac{E_{\alpha}}{R T}
$$

Using Eq. 8 to fit $\ln k$ and 1/T, a straight line can be obtained, which is shown in Fig. 6 . The linear slope is $-\frac{E a}{R}$ and the intercept is $\ln A$. The results are shown in Table 6.

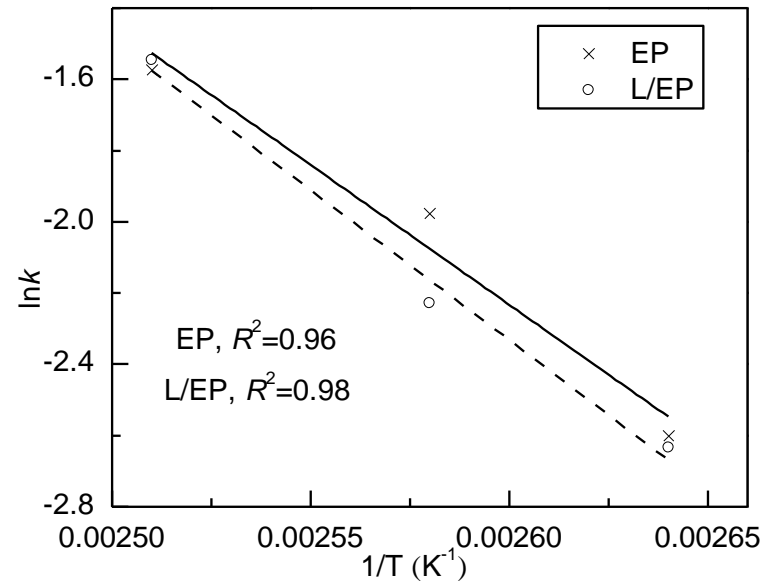

Fig. 6. Linear fitting relationship between reaction rate and temperature

Table 6. Activation Energy $E_{\mathrm{a}}$ and the Pre-exponential Factor $A$ of EP and L/EP Blends

\begin{tabular}{|c|c|c|c|}
\hline Sample & $E_{\mathrm{a}}(\mathrm{kJ} / \mathrm{mol})$ & $\ln A\left(\mathrm{~s}^{-1}\right)$ & Comment \\
\hline EP (DGEBA/Polyamine) & 65.3 & 18.18 & \\
\hline $\begin{array}{c}\text { L/EP } \\
\text { (lignin/DGEBA/Polyamine) }\end{array}$ & 70.0 & 19.55 & \\
\hline DGEBA/DGEBF/Jeffamine & $58.6^{a}$ & - & $\begin{array}{l}\text { Jeffamine-Polyoxypropylene } \\
\text { diamines }\end{array}$ \\
\hline DGEBA/DDM & $63.2^{b}$ & - & $\begin{array}{c}\text { DDM-4,4'- } \\
\text { Diaminodiphenylmethane }\end{array}$ \\
\hline DGEBA $/ m-P D A$ & 55 to $60^{c}$ & - & $m$-PDA-1,3-phenylene diamine \\
\hline DGEBA/MDA & $60.7^{d}$ & - & MDA-4,4'-methylenedianiline \\
\hline \multicolumn{4}{|c|}{$\begin{array}{l}\text { Source: a: Perrin et al. 2007; b: Deng and Martin 1994; c: Sbirrazzuoli et al. 2006; and d: } \\
\text { Mijovic et al. } 1992\end{array}$} \\
\hline
\end{tabular}

As shown in Table 5, the reaction rate constant $k$ increased with increased reaction temperature, $m+n$ was the overall reaction series. The value of $m+n$ for EP blends ranged from 3.015 to 4.058 , and the average value was 3.552. The value of $m+n$ for L/EP blends ranged from 4.182 to 4.544 , and the average value was 4.408 . 
The view of the autocatalytic reaction model is that the hydroxyl group generated from the ring opening reaction of epoxy resin will catalyze the ring opening reaction of the residual epoxy groups (Schawe 2002). The autocatalytic reaction is a three-molecularreaction (Sun and Zhang 2009). In the initial stage, the reaction between the epoxy resin and polyamine is the main reaction. At the same time, because there was a certain amount of tertiary amine nitrogen atom in the polyamine, and the tertiary amine nitrogen atom had the same effect as the hydroxyl catalytic ring opening reaction of epoxy groups, and there was an initial three-molecular reaction. As the ring opening reaction of epoxy resin progressed, the content of the hydroxyl group increased gradually, a four-molecular autocatalytic reaction occurred in the blends, and its proportion in the reaction mold was higher.

From the experimental results, the overall reaction order of EP blends ranged from 3.015 to 4.058. The presence of lignin in L/EP blends made the blends more complex. The active groups, such as hydroxyl and carboxyl, contained within EHL catalyzed the ring opening reaction of epoxy groups or participated in the reaction of epoxy groups directly, which made the blends exist at a higher reaction order in autocatalytic reactions. The overall reaction order of L/EP blends ranged from 4.182 to 4.544 , and the average reaction order was 4.408 according to the experiment data. However, Table 5 shows that the above curing reaction did not conform to autocatalytic reaction model absolutely, which showed the complexity of the curing reaction for the epoxy resin blended with highly purified enzymatically hydrolyzed lignin.

The data in Table 6 illustrate that the activation energy of epoxy resin/polyamine blends increased after the addition of lignin. This indicated that the addition of lignin to the epoxy resin/polyamine blends slightly lowered the reactivity of the curing reaction. This was possibly because a number of active hydrogen contained within EHL (such as phenolic hydroxyl, carboxyl, and ortho hydrogen on the phenolic hydroxyl, etc.) can combine with amino groups within the polyamine; thus, the polyamine reactivity decreased because of the consuming of amino. In addition, as a powder, the addition of lignin increased the viscosity of the blends and hindered the free diffusion of reactive functional groups, which led to the decreased reactivity of the blends. The above analyses were consistent with the experimental results for the curing temperature of $105^{\circ} \mathrm{C}$ and $115^{\circ} \mathrm{C}$. However, when the curing temperature increased, although these negative factors still existed, the catalysis ability and participation in the epoxy ring-opening reaction for the hydroxyl or carboxyl within EHL increased, which was conducive to the curing reaction.

\section{Mechanical Properties}

The variations of the bending strength and impact strength for the blends are shown in Fig. 7. The bending strength increased with the addition of lignin, and the blends showed approximately an $8 \%$ increase (to $80.4 \mathrm{MPa}$ ) with $5 \mathrm{wt} \%$ of the lignin. The improvement in the blending strength of the blends could be explained based on the aromatic ring structure in lignin molecular. However, the bending strength decreased slightly with increasing the content of lignin when the addition more than $5 \mathrm{wt} \%$, which may be due to the sharp increased viscosity and the fine form holes during the process of casting molding and curing. The impact strength decreased with increasing the content of the lignin. The possible reasons for the result are that the rigidity of blends reinforced obviously and the flexibility of molecular segments decreased with the introduced of aromatic ring structure. From the above results, the addition of lignin not only can promote the curing of epoxy 
resin/polyamine blends, but at the same time, the bending strength can be increased markedly, which is beneficial to expanding its application.

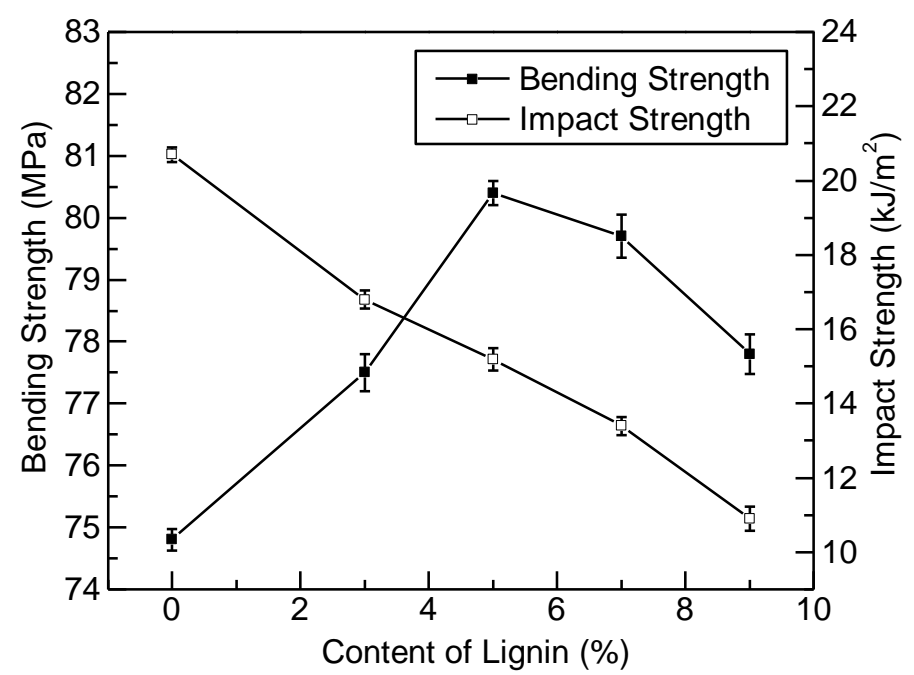

Fig. 7. Effects of lignin on the bending strength and impact strength of L/EP blends

\section{CONCLUSIONS}

1. The apparent activation energy of the epoxy resin/polyamine blends decreased from $288 \mathrm{~J} / \mathrm{g}$ to $282 \mathrm{~J} / \mathrm{g}$ with the presence of the lignin.

2. The presence of enzymatic hydrolyzed lignin was beneficial to the curing process of epoxy resin/polyamine blends at temperatures above $125^{\circ} \mathrm{C}$.

3. The addition of the lignin increased the final curing reaction conversion rate from 0.82 to 0.88 at $125{ }^{\circ} \mathrm{C}$ and improved the glass transition temperature for the epoxy resin/polyamine blend at $105^{\circ} \mathrm{C}, 115^{\circ} \mathrm{C}$, and $125^{\circ} \mathrm{C}$.

4. The curing kinetics for two blends was not in full compliance with the autocatalytic curing kinetic model, which showed the complexity of the curing reaction for the epoxy resin blended with highly purified enzymatically hydrolyzed lignin.

5. The bending strength of the L/EP blends increased with the addition of lignin with appropriate amount, and the blends showed approximately an $8 \%$ increase (to 80.4 $\mathrm{MPa}$ ) with $5 \mathrm{wt} \%$ of the lignin in the bending strength which is beneficial to expanding its application.

\section{ACKNOWLEDGMENTS}

The manuscript was supported by the Special Fund for Forest Scientific Research in the Public Welfare (20150452), the Fundamental Research Funds for the Central Universities (2572017EB06), and the National Natural Science Foundation of China (31670567). 


\section{REFERENCES CITED}

Abenojar, J., Encinas, N., Real, J. C. D., and Martínez, M. A. (2014). "Polymerization kinetics of boron carbide/epoxy composites," Thermochimica Acta 575, 144-150. DOI: $10.1016 /$ j.tca.2013.10.030

ASTM D 1084-16 (2016). "Standard test methods for viscosity of adhesives," ASTM International, West Conshohocken, PA.

ASTM D790-10 (2010). "Test methods for flexural properties of unreinforced and reinforced plastics and electrical insulating materials," ASTM International, West Conshohocken, PA.

ASTM D256-10 (2010). "Standard test methods for determining the Izod pendulum impact resistance of plastics," ASTM International, West Conshohocken, PA.

Cavdar, A. D., Kalaycioglu, H., and Hiziroglu, S. (2008). "Some of the properties of oriented strandboard manufactured using kraft lignin phenolic resin," Journal of Materials Processing Technology 202(1-3), 559-563. DOI:

10.1016/j.jmatprotec.2007.10.039

Deng, Y., and Martin, G. C. (1994). "Diffusion and diffusion-controlled kinetics during epoxy-amine cure," Macromolecules 27(18), 5147-5153. DOI:

10.1021/ma00096a043

Du, S., Guo, Z. S., Zhang, B., and Wu, Z. (2004). "Cure kinetics of epoxy resin used for advanced composites," Polymer International 53(9), 1343-1347. DOI: 10.1002/pi.1533

Feldman, D., and Banu, D. (1988). "Kinetic data on the curing of an epoxy polymer in the presence of lignin," Journal of Polymer Science Part A: Polymer Chemistry 26(4), 973-983. DOI: 10.1002/pola.1988.080260402

Feldman, D., Banu, D., Luchian, C., and Wang, J. (1991). "Epoxy-lignin polyblends: Correlation between polymer interaction and curing temperature," Journal of Applied Polymer Science 42(5), 1307-1318. DOI: 10.1002/app.1991.070420514

Ghaffar, S. H., and Fan, M. (2014). "Lignin in straw and its applications as an adhesive," International Journal of Adhesion and Adhesives 48, 92-101. DOI: 10.1016/j.ijadhadh.2013.09.001

Ghaffari, M., Ehsani, M., Khonakdar, H. A., Assche, G. V., and Terryn, H. (2012). “The kinetic analysis of isothermal curing reaction of an epoxy resin-glassflake nanocomposite," Thermochimica Acta 549, 81-86. DOI: 10.1016/j.tca.2012.09.021

Gosselink, R. J. A., Snijder, M. H. B., Kranenbarg, A., Keijsers, E. R. P., Jong, E. D., and Stigsson, L. L. (2004). "Characterisation and application of novafiber lignin," Industrial Crops and Products 20(2), 191-203. DOI: 10.1016/j.indcrop.2004.04.021

Harsch, M., Karger-Kocsis, J., and Holst, M. (2007). "Influence of fillers and additives on the cure kinetics of an epoxy/anhydride resin," European Polymer Journal 43(4), 1168-1178. DOI: 10.1016/j.eurpolymj.2007.01.025

Hatakeyama, T., Matsumoto, Y., Asano, Y., and Hatakeyama, H. (2004). “Glass transition of rigid polyurethane foams derived from sodium lignosulfonate mixed with diethylene, triethylene and polyethylene glycols," Thermochimica Acta 416(12), 29-33. DOI: 10.1016/j.tca.2002.12.002

Ibrahim, V., Mamo, G., and Gustafsson, P. J. (2013). "Production and properties of adhesives formulated from laccase modified kraft lignin," Industrial Crops and Products 45, 343-348. DOI: 10.1016/j.indcrop.2012.12.051

Karkanas, P. I., and Partridge, I. K. (2000). "Cure modeling and monitoring of 
epoxy/amine resin systems. II. Network formation and chemoviscosity modeling," Journal of Applied Polymer Science 77(10), 2178-2188. DOI: 10.1002/10974628(20000906)77:10<2178::AID-APP11>3.0.CO;2-0

Khalil, H. A., Marliana, M. M., and Alshammari, T. (2011). "Material properties of epoxy-reinforced biocomposites with lignin from empty fruit bunch as curing agent," BioResources 6(4), 5206-5223. DOI: 10.15376/biores.6.4.5206-5223

Laurichesse, S., and Avérous, L. (2014). "Chemical modification of lignins: Towards biobased polymers," Progress in Polymer Science 39(7), 1266-1290. DOI: 10.1016/j.progpolymsci.2013.11.004

Malutan, T., Nicu, R., and Popa, V. I. (2008). "Lignin modification by epoxidation," BioResources 3(4), 1371-1376. DOI: 10.15376/biores.3.4.1371-1376

Mansouri, N. E. E., and Salvadó, J. (2007). "Analytical methods for determining function groups in various technical lignins," Industrial Crops and Products 26(2), 116-124. DOI: $10.1016 /$ j.indcrop.2007.02.006

Mansouri, N. E. E., Yuan, Q., and Huang, F. (2011). "Characterization of alkaline lignins for use in phenol-formaldehyde and epoxy resins," BioResources 6(3), 2647-2662. DOI: 10.15376/biores.6.3.2647-2662

Mijovic, J., Fishbain, A., and Wijaya, J. (1992). "Mechanistic modeling of epoxy-amine kinetics. 2. Comparison of kinetics in thermal and microwave fields," Macromolecules 25(2), 986-989. DOI: 10.1021/ma00028a073

Musto, P., Abbate, M., Ragosta, G., and Scarinzi, G. (2007). "A study by Raman, nearinfrared and dynamic-mechanical spectroscopies on the curing behavior, molecular structure and viscoelastic properties of epoxy/anhydride networks," Polymer 48(13), 3703-3716. DOI: 10.1016/j.polymer.2007.04.042

Perrin, F. X., Nguyen, T. M. H., and Vernet, J. L. (2007). "Kinetic analysis of isothermal and nonisothermal epoxy-amine cures by model-free isoconversional methods," Macromolecular Chemistry and Physics 208(7), 718-729. DOI: 10.1002/macp.200600614

Saad, G. R., Elhamid, E. E. A., and Elmenyawy, S. A. (2011). "Dynamic cure kinetics and thermal degradation of brominated epoxy resin-organoclay based nanocomposites," Thermochimica Acta 524(1-2), 186-193. DOI: 10.1016/j.tca.2011.07.014

Saito, T., Perkins, J. H., and Jackson, D. C. (2013). "Development of lignin-based polyurethane thermoplastics," RSC Advances 3(44), 21832-21840. DOI: 10.1039/C3RA44794D

Sbirrazzuoli, N., Mititelu-Mija, A., Vincent, L., and Alzina, C. (2006). "Isoconversional kinetic analysis of stoichiometric and off-stoichiometric epoxy-amine cures," Thermochimica Acta 447(2), 167-177. DOI: 10.1016/j.tca.2006.06.005

Schawe, J. E. K. (2002). "A description of chemical and diffusion control in isothermal kinetics of cure kinetics," Thermochimica Acta 388(1-2), 299-312. DOI: 10.1016/S0040-6031(02)00041-2

Stewart, D. (2008). "Lignin as a base material for materials applications: Chemistry, application and economics," Industrial Crops and Products 27(2), 202-207. DOI: 10.1016/j.indcrop.2007.07.008

Sun, W., and Zhang, C. (2009). "Curing kinetics of bisphenol-A epoxy resin with polyamide by isothermal differential scanning calorimetry," Journal of Wuhan University of Technology 31(6), 28-31. DOI: 10.3963/j.issn.1671-4431.2009.06.008 Vafayan, M., Beheshty, M. H., Ghoreishy, M. H. R., and Abedini, H. (2013). "Advanced 
integral isoconversional analysis for evaluating and predicting the kinetic parameters of the curing reaction of epoxy prepreg," Thermochimica Acta 557, 37-43. DOI: 10.1016/j.tca.2013.01.035

Vyazovkin, S., and Sbirrazzuoli, N. (2006). "Isoconversional kinetic analysis of thermally stimulated processes in polymers," Macromolecular Rapid Communications 27(18), 1515-1532. DOI: 10.1002/marc.200600404

Vyazovkin, S., Burnham, A. K., Criado, J. M., Pérez-Maqueda, L. A., Popescu, C., and Sbirrazzuoli, N. (2011). "ICTAC Kinetics Committee recommendations for performing kinetic computations on thermal analysis data," Thermochimica Acta 520(1-2), 1-19. DOI: 10.1016/j.tca.2011.03.034

Wang, D. Z. (2001). Epoxy Resin and its Application, Chemical Industry Press, Beijing, China.

Wood, B. M., Coles, S. R., Maggs, S., Meredith, J., and Kirwan, K. (2011). "Use of lignin as a compatibliser in hemp/epoxy composites," Composites Science and Technology 71(16), 1804-1810. DOI: 10.1016/j.compscitech.2011.06.005

$\mathrm{Xu}, \mathrm{G} .$, Shi, W., and Shen, S. (2004). "Curing kinetics of epoxy resins with hyperbranched polyesters as toughening agents," Journal of Polymer Science Part B: Polymer Physics 42(14), 2649-2656. DOI: 10.1002/polb.20143

Yin, Q., Yang, W., Sun, C., and Di, M. (2012). "Preparation and properties of ligninepoxy resin composite," BioResources 7(4), 5737-5748. DOI:

10.15376/biores.7.4.5737-5748

Zhang, C., Wu, H., and Kessler, M. R. (2015). "High bio-content polyurethane composites with urethane modified lignin as filler," Polymer 69(1), 52-57. DOI: 10.1016/j.polymer.2015.05.046

Zheng, Y., Chonung, K., Wang, G., Wei, P., and Jiang, P. (2009). "Epoxy/nano-silica composites: Curing kinetics, glass transition temperatures, dielectric, and thermalmechanical performances," Journal of Applied Polymer Science 111(2), 917-927. DOI: 10.1002/app.28875

Zvetkov, V. L., and Calado, V. (2013). "Comparative DSC kinetics of the reaction of DGEBA with aromatic diamines. III. Formal kinetic study of the reaction of DGEBA with diamino diphenyl methane," Thermochimica Acta 560, 95-103. DOI: 10.1016/j.tca.2013.02

Article submitted: April 28, 2017; Peer review completed: August 3, 2017; Revised version received and accepted: August 31, 2017; Published: September 7, 2017.

DOI: $10.15376 /$ biores.12.4.7793-7806 